\title{
Review
}

\section{Fresh faces and business cases: The 10th IDM B2B marketing conference}

Journal of Direct, Data and Digital Marketing Practice (2013) 15, 93-98. doi:10.1057/dddmp.2013.43

\section{Forrester Research and Customer Experience}

\author{
Four myths about \\ customer experience
}

There are two things for which every business-to-business marketing department has a constant need: a robust argument for its budget and the talent to deliver its plans. At the IDM B2B Marketing Conference, held at the Commonwealth Club on 14 May and sponsored by D\&B, HP and Lead Forensics, both were in ample supply.

For emerging areas of focus, making the case for investment is always a challenge as there may not be any existing evidence to support the argument. Peter O'Neill, vice president and principal analyst at Forrester Research, tackled this head on in his keynote presentation, 'The business case for customer experience programmes'. 'The business case has to look at how customer problems are being dealt with and escalated, the value of retaining a customer and also the cost of dealing with customers', he pointed out.

Customer experience $(\mathrm{Cx})$ covers a lot of activities that are typically siloed, such as marketing, sales and customer service. But it also needs to consider how back office functions may have an impact on - and potentially deteriorate - the way a customer interacts with the business. Including these in considerations of a Cx programme is likely to expand the basis on which the argument for budget can be made.

'Customer lifetime value is an analysis point for putting economic value around Cx, balanced against the risk of churn', suggested O'Neill. 'B2B also has to think about channel partner loyalty. Modelling the benefits should include looking at increasing share of wallet, improved retention rates and the value of advocacy'.

This can be challenging for B2B marketers, since it expands the breadth of measurement and tracking required. But O'Neill pointed out that over half of all the chief customer officers who Forrester Research has encountered are employed by B2B companies - a clear sign that this sector has recognised the potential benefits of $\mathrm{Cx}$.

O'Neill offered a number of reasons for this: 'In B2B especially, most products are turning into a service. You are no longer following that cycle of make it, market it, sell it, you are actually developing into a relationship business. That has implications for marketing because the lifecycle we are managing is becoming much more complex and longer - that renewal transaction is always in front of us. That is why we feel customer experience is so important'.

O'Neill tackled what he described as four 'myths' that he believes have been holding back wider investment in Cx: 'Firstly, it's seen as a consumer 


\section{Customers now choose suppliers as individuals}

\section{Building an insight team at Unum}

\section{Finding influences on insurance buying}

thing. Well, people in business are consumers, too, and with "bring your own device" and the adoption of social media to provide feedback, they behave now much more as consumers'. Software and storage business EMC has realized that information passed around social media is affecting around 50 per cent of its business.

'Secondly, you hear that switching costs make $\mathrm{Cx}$ unimportant because it is not easy to change supplier quickly', he said. That is changing as technology becomes a commodity and end-users are increasingly becoming empowered to make their own decisions about which products and services to use. O'Neill gave the example of Maersk Line, which realized that individual shipping clerks working for logistics companies and manufacturers can switch provider very quickly, even if there is a corporate contract in place. It discovered that a 4 per cent increase in its Net Promoter Score gave a 1 per cent increase in revenue.

O'Neill added, 'Thirdly, B2B relationships are viewed as very complex, so the end-user experience is not considered that important. Fourthly, business partners often control the experience, so the brand doesn't have to'. This misses the fact that any problems with the brand itself have to be dealt with by the company. He noted that Cisco sells 85 per cent of its products through partners, and thus it now focuses on making sure they deliver a positive customer experience through training and monitoring those aspects of their partners' businesses.

End-user presentations always offer a valuable insight into how theoretical concepts and cases are translated into practical actions in the real world. This year's event provided two examples from ongoing developments based around better use of data - a major theme across the event.

One of these was given by Bill Mansfield, head of insight and analytics at Unum, one of those major companies you have never heard of. It is in fact a major provider of employee benefits insurance, writing 44 per cent of all the income protection schemes offered to staff by their employees. Two years ago, the company only had one-quarter of a full-time person working on its data.

The company's journey towards becoming evidence-based and datadriven started with acquiring data from Dun and Bradstreet and implementing some rudimentary tools to use them, such as Access. 'We use these data sources to look at the family trees of companies, identifying where they may have subsidiaries which are not insured or where the parent company has another division based in the UK that we are not selling to. Opportunities are benchmarked in a peer group, looking at what proportion of salary is insured by each company and therefore where an upsell opportunity might be found', said Mansfield.

'We have adopted a hypothesis-based approach', Mansfield explained. 'For example, one manager asked whether country of ownership had an influence on levels of insurance. So we looked for evidence about which countries have high levels of income insurance, what level of income is insured and how large the opportunity was'.

Mansfield's team developed through early projects carried out 'under the radar' in order to build its competency and proofs of concept. It focused 


\section{Building evidence for the business case}

\section{Global CRM at TNT Express}

\section{Central process, local knowledge}

on campaigns that would help its broker partners to write more business. 'A core piece of data is the number of employees in a business compared to the number covered by the employer - that is the size of the opportunity. State pension retirement age going up is another opportunity', explained Mansfield. Propensity models have been built using variables such as employee growth, profit growth and country of ownership to score prospects.

This steady development has led to a team of six people now being able to demonstrate a real impact on the business. 'Two years ago, we couldn't do a return on investment analysis - we had to rely on early, anecdotal indicators. Six months later, sales started to enter the funnel and that made more people interested. That is when we did the ROI analysis before anybody asked for it so we could calibrate the business case with real data and have it accepted by the finance department', said Mansfield.

A key element in the success of the project at Unum has been involving stakeholders early on and including them in a dialogue around the use of data and the value of analytics. This has allowed the team access to outcomes that provide the critical evidence necessary to the business case for ongoing investment - the insight team has now attracted one-quarter of all the internal funding being made by Unum in 2013.

A different scale of data-driven activity has been taking place at TNT Express, as business development manager Laurens Liezenberg explained. The global business has embarked on a two-year project focused on CRM and business growth within a larger business re-engineering programme intended to introduce common systems and processes to all of its operations. Its central marketing organization is arranged around three components: content, campaign management and 'suspect' management.

As Liezenberg told the conference, 'the main challenge for our suspect management was that we already had global databases, were capturing ever more information, but were not using it to its full extent. We had a high need to analyse it more effectively'. It took the step of working with D\&B in order to access its Market Insight database of 200 million organizations globally.

'We started with a high-level look at our market penetration in each country and compared that to the universe in D\&B's database, then narrowed it down to companies relevant to TNT, filtered in a number of ways so we can find the ones most likely to buy our solutions', he explained. Working with an external solution in this way allowed TNT to run analytics before taking any data into its in-house CRM system. 'It has proved more successful than we expected. We are still able to find a lot of companies that are not on our radar yet, despite being in the market for years', said Liezenberg. Data quality within TNT's self-built marketing database has also improved as a result of matching against external data.

As well as working on the value of its data assets, the project has also focused on improving how it carries out marketing. Previously, local operations ran their own campaigns with no central oversight - now the business is steadily bringing all of its territories into the same system.

'The first thing we did two years ago was to create a model of governance, then selected expert users from across the 60 countries in the 


\section{No spend without analysing potential}

\section{One Young World}

\section{Success is what you pass on}

global organisation. We ran pilots in some of those, with the other countries following once they had developed the new processes', explained Liezenberg. 'This year we have got 35 countries using the solution - our goal is to have every country live by the end of 2013'.

Automation of many of the campaign selection processes has improved efficiency and oversight, rather than local marketers making their own selections in offline Excel tools. Liezenberg explained, 'Every country has direct access to the database because we can't understand the market from the centre. They run their own analysis, then based on their models we assess the potential and leads go to account managers or local sales once we have qualified those suspects. We don't spend much money on companies until we are sure there is potential'.

By targeting efforts to companies that demonstrate genuine potential, as well as identifying new suspects that it had not previously discovered, TNT has been achieving steady business growth even in markets where it is well established, such as the United Kingdom. The next step is to take its data learnings into other areas of its marketing. Said Liezenberg, 'We are now looking into algorithms to drive our campaign management system and optimise campaigns'.

What these presentations demonstrated was the steady evolution of B2B marketing around proven techniques such as database marketing, as well as the transformational potential of new concepts like customer experience. In many cases, both of these are happening at the same time and in the same companies, giving some sense of just how challenging the life of a B2B marketer has become.

A further pressure on marketers is the arrival of a new generation of young colleagues with their own views on how business, marketing and the world in general ought to be run. Under the watchful eye of One Young World (OYW) co-founder, Kate Robertson, who is also group chairman of Havas Worldwide UK, three of the 'Future Generation of Marketers' took to the stage to present their views, concerns and challenges to the audience. Their take on how marketing and business needs to engage with the young adult marketplace was both challenging and fascinating.

Lawrence Gaston, OYW ambassador at Barclays, pointed out that 'for previous generations of companies, it was all about being the biggest, best and most profitable. They were judged on what they offered as a product or service. The goal was to get bigger and consume more'.

That growth has been achieved without much attention being paid to social fairness or sustainability. 'Our priorities are completely different to the previous generation's', Gaston pointed out. 'How do we ensure success is not at the expense of the people a business interacts with? This generation will be measured by what is passed on to the next generation'.

One of the issues for brands trying to relate to this shift in focus is that 'it can be perceived as demanding more than the consumer has a right to', said Gaston. 'Brands that will do well turn that into a set of corporate values that we can connect to. It is a win-win'. Consumers typically define themselves through three main brands. The generation represented by OYW is likely to choose a very different slate for its self-actualisation than 


\section{Creating a shared culture}

\section{A better world through listening to young leaders}

\section{'Allow us to be all that we can be'}

its parents - the shortlist will be made up of brands that younger consumers feel able to trust. That trust will be based not just on the statements that brands make about themselves. 'There is no longer a separate public and private image. Anything you do becomes public', warned Gaston.

Consumption is only one dimension of this trust - it also comes into play for this generation as it enters the workforce. 'It is more powerful if you create a shared objective culture', explained Ray Farnan, OYW ambassador at PwC. This involves explaining to staff that 'our aim is to do $\mathrm{x}$, so your role is to do y' and helps to attract young employees.

He stressed that for many of his generation, financial reward is only part of the deal - enjoying work and having job satisfaction are just as important. Helping a business to change its culture would be a tremendous reward, even if this cohort lack experience. 'What young people lack, we make up for in innovative thinking and enthusiasm', argued Farnon.

Just as lifestyle is no longer simply about consumption, his generation also do not see themselves as defined by a particular job. 'We are looking for increased flexibility in the workplace. Our generation wants to move jobs more often and get a wider experience. That is also reflected in the way we want to work - remotely, via online meetings, at multiple locations', he said.

OYW was created 4 years ago to give young leaders of the future accelerated access to the top tiers of business and government. 'If the people at the top could listen to the views of young leaders, it would start to drive a better world', noted Robertson. Unilever is using its OYW ambassador to deliver its sustainable living plan, which is changing its business model, for example.

In part, the youth ambassador programme was created out of a recognition that trying to achieve change has to be based as much on actions as on words. 'David Jones, global CEO of Havas, said that for some time he had believed that as a creative industry, advertising had the talent to effect positive change', said Robertson.

Many of the changes advertising was responsible for were already positive, even if they were just which car or TV to buy. When it came to the bigger picture, however, 'he didn't want the global CEOs of companies we work for to ask what we're doing and for the answer to be "nothing"' OYW was born out of this perception and now has 3,500 ambassadors in its fourth year and is able to attract the likes of Desmond Tutu and Kofi Annan to its annual event.

That also underlines another feature of this generation. 'We are shamefully well connected and will tell everybody', pointed out Catherine Thompson, OYW ambassador at Unilever. Being involved in conversations with brands is non-negotiable as a result. She noted that 'Twitter has changed the way the world works', pointing to the way a personal protest against youth unemployment in Tunisia became the trigger for the Arab Spring of 2012 via the micro-blogging service.

'Allow us to be all that we can be. Brands need to fit into our world', said Thompson. That demands a bigger shift than just adopting 
youth-friendly marketing. 'Your purpose has to be bigger than a campaign or a comms plan. It is the reason why you open your doors in the morning'.

Not everybody in that corporate audience has been convinced.

Robertson pointed out that 'there are some business that really don't care. But when a business doesn't care, it is a bad business and it is going to be in trouble. Many have already found that out in the last four years'. By contrast, she noted that the new CEO at Barclays is making changes that are 'the most courageous thing I've ever seen in business'.

Hearing directly from representatives of the young adult age group was undoubtedly refreshing. It was also challenging and even threatening, since there are big changes being demanded from the existing business model. What is also notable is that the OYW ambassadors are working to achieve change from within the very corporations that engineered the problems that concern them. This is not a rebellion, but it might still be a takeover.

David Reed FIDM 